\title{
Predatory journals: a different pandemic
}

\author{
George A. Taylor ${ }^{1,2}$ (1)
}

Received: 17 September 2020 / Revised: 7 October 2020 / Accepted: 17 November 2020 / Published online: 6 January 2021

(C) Springer-Verlag GmbH Germany, part of Springer Nature 2021

Dear Dr. Dr.Gerge-A-Taylr,

Greetings from Journal of Imaging and Interventional Radiology!

We have gone through your publication was monumental, as it is gaining a good readership, we are privilege to invite eminent authors like to to share your valuable research for upcoming issue in our Journal.

\section{Dear Dr. George A. Taylor,}

Hope I am not irritating you with my email. If yes sorry for the inconvenience caused by my end. I am Brando Marlon working as an assistant manager of Journal "Peer Research Nest" sends invitation to eminently like you to help me in growth of my Journal. I know that you are getting hundreds of solicited email and got fed up with the invitations that you have got.

These examples are two of the more interesting e-mails I have received from predatory or fake journals, writing to solicit an article, or offer a position on an editorial board or as a manuscript reviewer.

What are predatory journals? In 2019, a consensus committee writing in Nature defined predatory journals as "entities that prioritize self-interest at the expense of scholarship and are characterized by false or misleading information, deviation from best editorial and publication practices, a lack of transparency, and/or the use of aggressive and indiscriminate solicitation practices" [1].

According to 2015 estimates, approximately 8,000 predatory journals churn out more than 400,000 items a year, and the number of articles published by these journals steadily increased to approximately 420,000 in 2014 from 53,000 in

George A. Taylor

TaylorG2@CHOP.edu

1 Department of Radiology, Children's Hospital of Philadelphia, 3401 Civic Center Blvd., Philadelphia, PA 19104-4399, USA

2 Department of Radiology, Boston Children's Hospital, Boston, MA, USA
2010 [2]. The estimated size of the predatory journal market is $\$ 74$ million [2]. To sustain this growth, predatory journals have to be aggressive in obtaining paying contributors. In the 12 months ending Aug. 15 of this year, I collected and categorized all of the unsolicited invitations I received to participate in journal activities as a writer, reviewer or editor. Data I collected included the entity name, primary focus of interest, number of requests, and deadline to submission, as well as variations in salutation, the spelling of my name, and unusual grammar.

I received a total of 236 unsolicited requests from 164 journals, an average of 4.6 requests per week for the entire year. They exhorted me to submit manuscripts (203 requests), act as a reviewer $(n=28)$ or join their editorial board $(n=5)$. The deadlines posted for manuscript submission varied widely, from 12 days before the e-mail was sent to 365 days in the future. In addition, I received individual solicitations from publishers suggesting that I allow them to ghost write a book on any topic of my choosing, and another offering to "create a new article, possibly covering some basic details of the published paper I have seen online ... written and developed by [omitted here], in close collaboration with you. You will work less than one hour."

The majority of the journals (56\%) focused on some medical specialty unrelated to pediatrics or radiology, such as internal medicine, surgery, pathology or dementia research. An additional $18 \%$ focused on pediatrics or neonatology, and only $15 \%$ of journals focused on imaging. The remaining soliciting journals published in unrelated biomedical fields such as dentistry, virology and pharmaceuticals, or were in areas completely out of the realm of biomedical research (economics, business development, linguistics).

Most e-mails did not include a specific address, or even a country of origin. However, a sampling of United States addresses showed dubious locations, including a used car lot, an insurance agency, and a rural road in the state of Delaware. Most annoying was the misspelling of my name, (Respected Doctor. Geroge A. Tyalor) or even having the e-mail addressed to another person (my son, a former co-author), or simply "TO:lq12131010." 
Predatory journals began appearing widely in 2008-2009, and their rise has been linked to a growing dissatisfaction with traditional subscription-based journals [3]. Fees charged to libraries for institutional subscriptions might cost thousands of dollars per year. While electronic publishing has nearly eliminated the costs of mailing print copies, library subscription fees for many journals have actually increased. McCabe and Snyder [3] found that profit-maximizing journals would be more likely to adopt an open access model the lower the journal's market power, the lower the marginal cost of serving a reader, and the higher the distribution of author benefits.

These developments have contributed to the rise of open access journals for which content is available free of charge to readers, and revenue to cover publication costs comes from authors. The open-source nature of open access journals made it easy for predatory journals to mimic legitimate journals and proliferate [4].

Predatory journals represent a serious threat to scientific integrity because of the lack of proper scientific review of submitted manuscripts. Publication of poor-quality research findings can lead to unsafe practices with no benefit to patients, and might reward unethical and unscientific conduct [5]. John Bohanon [6], a journalist for Science, exposed how flawed the review process could be in predatory journals. He submitted a fabricated and highly flawed research paper to open access journals $[4,6]$. Of the 255 copies submitted, the paper was accepted 157 times. Sixty percent showed no sign of having been peer-reviewed; even when a review did occur, many neglected to evaluate the study's scientific validity, focusing only on layout, format and language [6].

Most predatory journals are located in the developing world, even if they claim to be in the United States or United Kingdom, and many journals provide incorrect postal addresses $[4,7]$. Most of the publications submitted to predatory journals originate from authors in developing countries. However, this is not exclusively an issue affecting the developing world. In one study, more than half the corresponding authors were from high- and upper-middleincome countries as defined by the World Bank. In their sample, the United States produced more articles than all other countries save India. Authors also found that among the $17 \%$ of articles that reported a funding source, the most frequently named funder was the United States National Institutes of Health (NIH) [7, 8].

According to Moher et al. [8], many of these journals are not indexed, and therefore unlikely to be read. As a result, the efforts of authors submitting their work, as well as funds used to support these efforts, are most likely wasted. According to Moher et al.: "Individuals agreeing to be studied have the rightful expectation that their participation could benefit future patients. Furthermore, the use of animals for research is rationalized on the assumption that experiments will contribute valuable information. Neither is likely when studies are not rigorously conducted and subjected to equally rigorous review prior to publication" [8].

A number of factors might influence the decision to publish in predatory journals. Acceptance rates for many genuine journals are low, in the $10-15 \%$ range, making publication in genuine journals difficult. In addition, a survey of authors in predatory journals showed that scholars in the developing world thought that reputable Western journals might be prejudiced against them, were unaware of the poor reputation of the journals, felt strong pressures to "publish or perish," and felt they had a lack of research proficiency [4].

While distinguishing legitimate open access journals from predatory journals might be difficult, certain characteristics are helpful. Predatory journal homepages frequently contain spelling errors and distorted or unauthorized images, promote bogus impact metrics, and have editors or editorial board members whose affiliation with the journal is unverified. In addition, predatory journals charge much lower fees $(\$ 63-\$ 150)$ compared to legitimate open access journals $(\$ 800-\$ 2,205)$ [9]. Another hallmark of predatory journals is manipulative spam that praises a potential author's earlier publications and asks for a submission [10].

What can we do to minimize the likelihood that our trainees and young faculty submit manuscripts to predatory journals? The International Federation for Emergency Medicine Research Committee has suggested an overall approach for choosing journals for possible publication [5]:

1. Submit your work to journals that you would normally find interesting and relevant.

2. Reach out to colleagues and mentors for suggestions of journals where your work will fit best. Engage your university librarian to find legitimate impact factors and genuine journals.

3. Be honest about methodological flaws in your own work. Reviewers failing to see those limitations is a key indicator that the journal is predatory.

4. Search for the journal title in the National Library of Medicine (NLM) catalogue for journals referenced in the National Center for Biotechnology Information (NCBI) databases. These databases contain information about journal indexing in MEDLINE, PubMed and PubMed Central.

5. Check whether the journal is listed in the Directory of Open Access Journals (DOAJ).

6. Check whether policies and procedures are transparently listed on the journal's website.

7. Consider reading articles in the journal before submitting. Look for grammatical and spelling errors, poor-quality science and shoddily maintained websites. 
Finally, "Think. Check. Submit." is an initiative that offers important checklists that help guide authors in choosing appropriate journals in which to publish their papers [11].

\section{Compliance with ethical standards}

Conflicts of interest None

\section{References}

1. Grudniewicz A, Moher D, Cobey KD et al (2019) Predatory journals: no definition, no defence. Nature 576:210-212

2. Shen C, Björk B-C (2015) 'Predatory' open access: a longitudinal study of article volumes and market characteristics. BMC Med 13: 230

3. McCabe M, Snyder C (2004) The economics of open-access journals. George J. Stigler Center for the Study of the Economy and the State, University of Chicago, Chicago. Online book. http:// citeseerx.ist.psu.edu/viewdoc/download?doi=10.1.1.173. 1838\&rep=rep1\&type=pdf. Accessed 14 Sept 2020
4. Kurt S (2018) Why do authors publish in predatory journals? Learn Publ 31:141-147

5. Hansoti B, Langdorf MI, Murphy LS (2016) Discriminating between legitimate and predatory open access journals: report from the International Federation for Emergency Medicine Research Committee. West J Emerg Med 17:497-507

6. Bohanon J (2013) Who's afraid of peer review? Science 342:60-65

7. Demir SB (2018) Predatory journals: who publishes in them and why? J Inf Secur 12:1296-1311

8. Moher D, Shamseer L, Cobey K (2017) Stop this waste of people, animals and money. Nature 549:23-25

9. Shamseer L, Moher D, Maduekwe O et al (2017) Potential predatory and legitimate biomedical journals: can you tell the difference? A cross-sectional comparison. BMC Med 15:article 28

10. Beale $J$ (2016) Best practices for scholarly authors in the age of predatory journals. Ann R Coll Surg Engl 98:77-79

11. Acreman B, Becquet G, Bjørnshauge L et al (2020) Think. Check. Submit. Choose the right journal or publisher for your research. Website. https://thinkchecksubmit.org. Accessed 7 Oct 2020

Publisher's note Springer Nature remains neutral with regard to jurisdictional claims in published maps and institutional affiliations. 